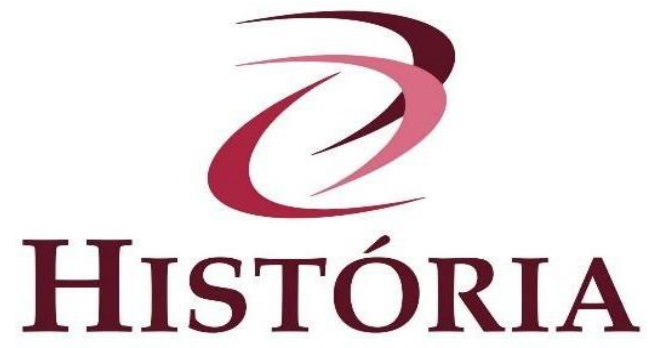

debates e tendências

\title{
Espacio e historia en la programática política de la historiografía del Revisionismo 'anterior' al Revisionismo en la Argentina
}

\author{
Space and history in historiography's programmatic politics of Revisionism \\ 'prior to' the Revisionism in Argentina
}

\section{Espacio e história na programação política da historiografia do Revisionismo 'antes' do Revisionismo na Argentina}

Eduardo Alberto Escudero ${ }^{\mathrm{i}}$

\begin{abstract}
Resumen: Este artículo propone el examen de las ideas políticas e historiográficas que J. Francisco V. Silva (Córdoba, Argentina, 1890-1978) vertiera en su intervención intelectualconducente a explicar las causales de la "desmembración territorial" de la Argentina y el ex Virreinato del Río de la Plata desde 1810. Se trata de comprender la mencionada textualidada la luz del contexto de la Primera Guerra Mundial y en articulación con la revitalización del pasado hispano en América, que muchos intelectuales de la coyuntura propusieron a contramano del relato de la historia liberal heredada del siglo XX. En ese sentido, este trabajo se aboca a leer la manera en que Silva representa un eje sensible a la imaginación revisionista, como es el de la desmembración del ex virreinato, y su manera metodológica de abordarlo, aduciendo la relevancia de la historia y de la geografía desde un residual positivismo, al concebir a la primera como equivalente al ambiente físico que modela el tipo racial y a la segunda como proceso por el que se elaboran las determinaciones sociales. Palabras clave: Historiografía. Panhispanismo. Revisionismo.
\end{abstract}

Resumo: Este artigo propõe o exame das ideias políticas e historiográficas que J. Francisco V. Silva (Córdoba, Argentina, 1890-1978) colocou em sua intervenção intelectual para explicar as causas do "desmembramento territorial" da Argentina e da Ex-Vice-Reino do Río de la Plata desde 1810. O objetivo é compreender a referida textualidade à luz do contexto da Primeira Guerra Mundial e em conjunção com a revitalização do passado hispânico na América, que muitos intelectuais da situação propuseram ao contrário da história da história liberal herdada do século XX. Neste sentido, este trabalho centra-se na leitura de como Silva representa um eixo sensível ao imaginário revisionista, como o desmembramento do antigo vice-reinado, e a sua forma metodológica de o abordar, aduzindo a relevância da história e da a geografia de um positivismo residual, ao conceber o primeiro como equivalente ao ambiente físico que modela o tipo racial e o segundo como um processo pelo qual as determinações sociais são feitas.

Palavras-chave: Historiografia. Panhispanismo.Revisionismo. 


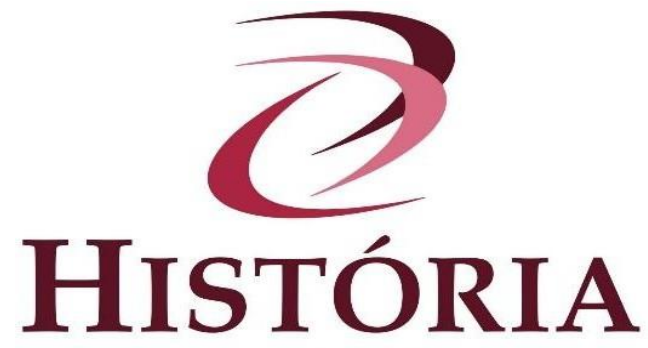

debates e tendências

Abstract: This article proposes an exam of the political and historiographic ideas which J. Francisco V. Silva (Cordoba, Argentina, 1890-1978) poured into his intellectual intervention conducive to an explanation of the grounds of the "territorial dismemberment" of Argentina and the former Rio de la Plata Viceroyalty since 1810. It is an attempt to comprehend the mentioned textuality in the light of the context of the First World War and in articulation with the revitalization of the Hispanic past in the American continent, which many intellectuals from such situational context proposed in opposition to the narratives by the liberal history bequeathed from the 20th century. In that respect, this work focusses on a reading of the way in which Silva represents an axis which is sensitive to the revisionist imagination, such as the dismemberment of the former Viceroyalty, and his methodological fashion of dealing with it, explaining the relevance of geography and history from a residual positivism, when conceiving the former as an equivalent to the physical environment which models the racial type and the latter as a process by means of which the social determinations are made.

Keywords: Historiography. Panhispanism. Revisionism.

\section{Introducción}

"Estudiar la causalidad de la desmembración es procurar distinguir qué influenciasy qué factores estimularon y provocaron este fenómeno histórico. El estudio de la vida se agita sobre dos bases que hacen posible su fenomenología, conviene a saber: la Geografía y la Historia, lo que equivale, dualmente, al ambiente físico que modela el tipo racial, y a la elaboración de las determinaciones sociales" (SILVA, 1918, p. 59)

Desde la primera década del siglo XX, el historiador cordobés J. Francisco V. Silva (Córdoba, Argentina, 1890-1978) articuló espacios intelectuales e ideas políticohistoriográficas entre Argentina y España y fue partidario de un proyecto histórico capaz de hacer frente al panamericanismo. Enunciando la confraternidad de los pueblos hispánicos, el intelectual dedicó tempranamente una encendida historiografía para amonestar, representaciones del pasado mediante, la situación de crisis abierta por la Primera Guerra Mundial y las pretensiones del imperialismo norteamericano, proyectando una unión hispana, con régimen federal, bajo el imperio moral del rey de España (ESCUDERO, 2018, pp. 19-37).

El otro importante objetivo de esta mediación intelectual era combatir al liberalismo decimonónico, representado en la factura de la política argentina y americana desenvuelta desde 1810. Esto se articulaba con una particular perspectiva de la historiografía argentina, decididamente negativa del rumbo seguido por los estudios históricos desde el siglo XIX 


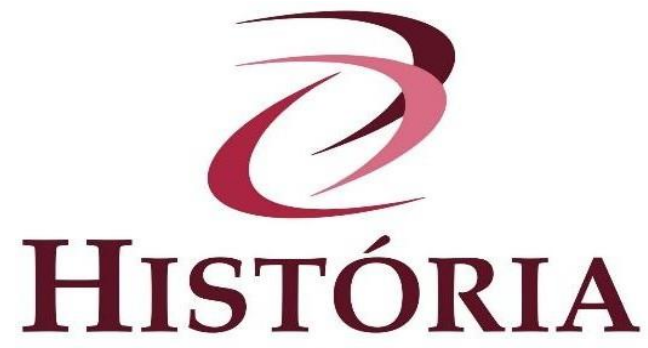

hasta 1916, por "desviación” de la verdad. Al parecer de J. Francisco V. Silva, se había redactado una historia argentina viciada por la presencia de un solo criterio, el del "puerto de Buenos Aires". Era una posición política e historiográfica determinante y valiente, plausible de vincular con la de otros intelectuales latinoamericanos que abonaron la imaginación histórica desde el fraguado de una verdadera alternativa interpretativa al "relato" liberal (ESCUDERO, 2018, p. 25 y ss.).

Silva afirmaba en sus textos de juventud que la historiografía porteña había sido la causa principal de la "constante falsedad" que se advertía en el juicio acerca de los hombres y los hechos del pasado nacional. Compartía, además, con los tempranos historiadores y ensayistas revisionistas, aunque en este punto también es posible filiarlo con los posteriores (ESCUDERO, 2018, p. 25 y ss.), la crítica a la educación histórica: "no podemos ocultar al niño hispano el pasado territorial glorioso de su Pueblo [sic], que comienza más lejos, en 1492 sin un ápice de duda, escamoteándoselo —como viene ocurriendo por los historiadores patriotas desde 1810 - entre los convencionalismos pusilánimes y las sensiblerías decadentes" (SILVA, 1918, p. 137); y la desactualización de una historia que renegaba del antecedente español. ${ }^{\text {ii }}$

En ese sentido, para el historiador los niños en edad escolar habrían de aprender la historia de sus países para beber ideales nacionales que debían "nutrir el alma de las generaciones hispánicas", aunque no a partir de las biografías idealizadas de sus gobernantes y héroes. Silva consideraba que ello no era "Historia", sino sólo "el ensalzamiento de sus éxitos y el encubrimiento de sus fracasos", en narraciones del pasado de la América española y de Argentina llenas de "genios y héroes": un verdadero cuento para "teatro de niños". A contramano, en su acción desmitificadora planteaba que durante el siglo XIX casi todos políticos habían sido ineptos y carentes de ideales, y se lamentaba que luego de ocupar el poder desde 1810 siguieran "mereciendo aduladora alabanza, en prueba de un falacísimo [sic] concepto nacionalista, como si éste fuera un juego de compadres". Afirmaba, sin más, que era urgente que se acabara la difusión de las "infantiles mentiras históricas convencionales y patrióticas localistas" que regían desde la Independencia en toda la América española, en virtud de la recuperación del “decoro nacional hispánico” (SILVA, 1918, p. 116). 


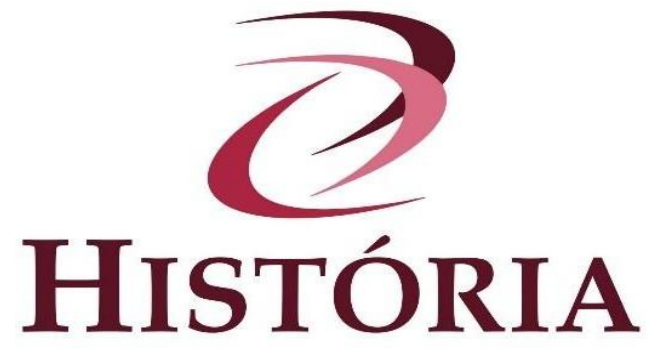

Convencido de que la historia debía ser un elemento vital de conciencia para la acción, sobre todo en tiempos de crisis como los abiertos por la Primera Guerra Mundial, Silva expresaba claramente que los argentinos tenían la obligación de explicar la historia argentina en sus acciones más visiblemente humanas y en sus reacciones más inexplicables como productos del genio "pero sin pretender erigirnos vanidosamente como si fuéramos una excepción en el Mundo". Era un llamado a considerar que el proceso del desarrollo político y social del país debía ser restituido en una interpretación global de la historia mundo hispánico. De esta manera, pondrá consecuentemente en discusión el "criterio dominante en toda América española desde 1810", según el cual se le había asignado "una tonalidad sombría y romántica a la Conquista, desvirtuándola", además de rodear "de gesto patético al siglo XIX, quitándole su verdadero espíritu" (SILVA, 1918, p. 116).

En lo subyacente de su crítica, Silva amonestaba al liberalismo económico derivado de la Europa no española, que explotaba y comerciaba las inmensas riquezas vírgenes naturales con el oro de sus mercados consumidores, "movidos por el esfuerzo productor de sus proletariados, revolucionados en la adquisición de sus reivindicaciones sociales". Esa sensibilidad social, animada por el panorama de su presente, lo llevaba a resignificar, a poner en valor, al pueblo como sujeto histórico. Se trataba del pueblo argentino que había querido genuinamente y a pesar de los extravíos de los hombres del poder en Buenos Aires, alcanzar su libertad en 1810: "[libertad] que se difunde por pampas lejanas y cordilleras abruptas entre mares inmensos y que siguió el símbolo pagano de sus indios ancestrales: el Sol de Mayo, que campea libre en la bandera bicolor, surgida en las horas patricias del peligro y del triunfo, como prenda de paz con generaciones fronterizas y naciones remotas, para poder vivir feliz en el Mundo y fraternal con los hombres sin banderías" (SILVA, 1918, pp. 121-122).

Esa enérgica diatriba al pasado-presente de la Argentina, que J. Francisco V. Silva llevaba a España para esparcir y activar la empresa política del panhispanismo, implicaba, como se dijo, una rectificación del relato hegemónico de su historia y las matrices culturales que se hallaban vigentes a principios del siglo XX. Puede concebirse que la sensibilidad experimentada por el autor que se estudia se liga a la atmósfera tan interesantemente planteada por Andrea Pascuaré al estudiar al "viaje transoceánico" como un lugar central en la formación de una "imaginada comunidad cultural hispanoamericana". Tanto en el caso de las 


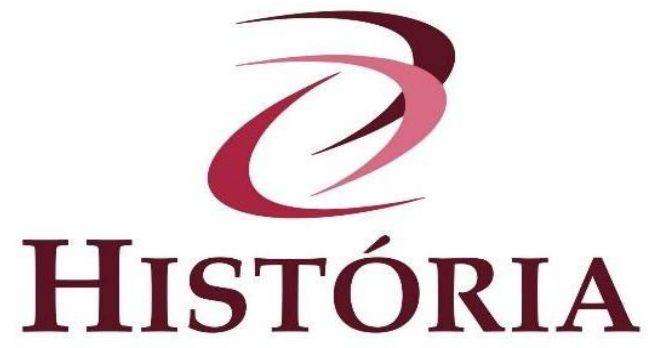

misiones culturales de escritores e intelectuales de renombre, como de los viajes formativos y de contacto cultural de otros personajes tal vez menos visibles o invisibilizados por el canon y la historia de la historiografía, aconteció una verdadera "política de acercamiento cultural dentro del mundo hispánico de la que saldrían una abundante gama de representaciones recíprocas" (PASCUARÉ, 2000, p. 282).

La mencionada autora expresa, además, que de esa experiencia se irradió un rechazo profundo al positivismo, en acto de diferenciarse de los valores de la sociedad capitalista, en la reivindicación de la espiritualidad y en la idea de poder estrechar vínculos con las naciones con las que se compartía una tradición, una raza, una lengua, para así poder "demostrar la fuerza espiritual de la tradición hispana frente al poderío material anglosajón" (PASCUARÉ, 2000, p. 283). Así, se visualiza a J. Francisco V. Silva yendo a España desde su Córdoba argentina para señalar el erróneo devenir de "las superabundancias económicas que muchos halagan traidoramente por ocurrir la adquisición fácil de la riqueza", en tanto su disfrute “enerva viriles energías", en el sentido de que desvirtuaba moralmente la nación. Efectivamente, su ángulo cultural y político cuestionaba a los convencionalismos europeos, aquellos que "tanto desorientan suicidamente al preferir de modo sistemático y desmedido las exterioridades extranjeras por las costumbres genuinamente hispanas" (SILVA, 1918, pp. 121-122).

Entre los años 1914 y 1918 J. Francisco V. Silva dedicó una profusa intervención historiográfica y política entre España y Argentina para alcanzar los objetivos que ya se

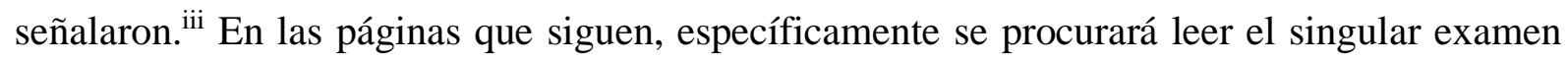
de lo que llamó “desmembración territorial”, a cuentas de operacionalizar la relación entre espacio y relaciones sociales, entre geografía e historia, y la hora de argüir las razones de la decadencia histórica que subsumía a la Argentina luego del camino histórico errático resuelto desde 1810. En ese sentido, Silva consideraba ineludible hacer de la geografía y de la desunión territorial los vértices que cabalmente evidenciaran y explicaran la crisis moral y política de la Hispanoamérica del siglo XIX. Evidenciando resabios positivistas, el historiador afirmaba que el estudio de la vida debía sostenerse sobre "las dos bases de su fenomenología". Así, tanto la Historia como la Geografía, es decir la elaboración de las 


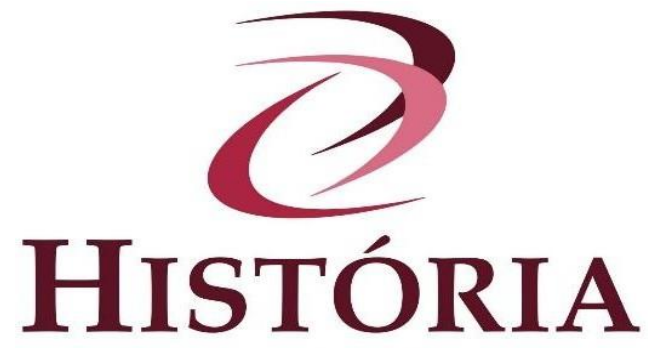

debates e tendências

determinaciones sociales y el ambiente físico que modela el tipo racial, responderían cabalmente a la exégesis del problema a considerar.

De esta manera indicaba que la "Configuración geográfica que puede representar en la determinación histórica, es materia cuyo interés aumenta, si ha de ser posible buscar en la acción humana un supuesto más hondo y más real, que el que pueda proporcionar un albedrío reflexivo con sus proposiciones" (SILVA, 1918, p. 60). En esa dirección, Silva explicaba que la Historia no era un resultado invariable que tenía que aceptarse definitivamente, sino que "su obra es rectificable en aquello lógico de alterar" (SILVA, 1918, p. 60); y la consideraba una resultante social de la geografía y de la raza. Sin embargo y de modo muy interesante, el historiador admitía la posibilidad del cambio histórico como producto racional de una valoración de la realidad que instigaba la toma consciente de nuevas determinaciones colectivas.

Con todo, Silva entendía que el estudio de la Geografía y de la Historia facilitaban la comprensión y determinación de una nueva hora para los pueblos hispánicos, momento de la reelaboración de una identidad latente para, finalmente, dejar de "dar pábulo al patriotismo agresivo de mero intelectualismo que en Argentina propaga el puerto de Buenos Aires desde 1810" (SILVA, 1918, p. 36). El historiador impugnará a lo largo de todo su estudio lo que llama "la política porteña", que conspirativamente imaginaba "adueñada de Argentina" y ocultadora de "las desmembraciones virreinales, ya que ellas se produjeron en función de la desgraciada actuación dirigente de Buenos Aires, la cual mantienen en secuestro sus pseudohistoriadores" (SILVA, 1918, p. 36). De esta manera, la historia se ponía al servicio de la política y, con ello, enaltecía sus potencialidades vitales.

Este revisionismo "anterior al Revisionismo" en la Argentina trazaba una línea de corte respecto de las tradiciones historiográficas vigentes y también imaginaba otros territorios, consecuente con los alcances de su completud política. No se dispone en esta oportunidad del espacio necesario para ofrecer un desarrollo acerca de la expresión utilizada, que sin dudas puede derivar en una extensa discusión. En líneas generales, con este anacronismo metafórico se hace referencia a las historias que en la Argentina, anticipadamente al año 1934 y posiblemente ya desde finales del siglo XIX, objetaron con mayor o menor grado de moderación a la historiografía liberal legitimada desde Buenos 


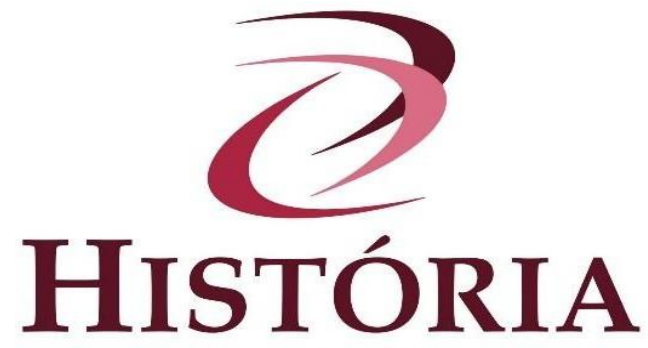

debates e tendências

Aires. ${ }^{\text {iv }}$ Podrían considerarse, en ese sentido, tanto a las historiografías provinciales reivindicatorias de los, acontecimientos, figuras y caudillos locales(BUCHBINDER, 2008; QUIÑONEZ, 2009; ESCUDERO y ROJAS, 2014; ROJAS, 2017; MICHELETTI, 2015), como a las relecturas sociológicas en clave positivista acerca del fenómeno rosista (PÉREZ AMUCHÁSTEGUI, 1980; CATTARUZZA y EUJANIAN, 2010), como a la historiografía constitucionalista del Centenario en su afán reformista. El caso de J. Francisco V. Silva es singular puesto que apuesta a la revisión histórica acudiendo a una imaginación históricoterritorial de corte subcontinental antes que localista, entre otras derivas, sin descuidar el acendrado apego a la tradición de su Córdoba del Tucumán(CHIARAMONTE, 2014; CHIARAMONTE y BUCHBINDER, 1992).

\section{Imaginación histórico-política, hispanofobia y pasado-presente}

Todo el bosquejo panhispanista, articulando los saberes antes mencionados, se hallaban desenvueltos en la escritura de J. Francisco V. Silva en pos de una determinada representación del siglo liberal y de una praxis política, un programa a desarrollar. La imagen del siglo XIX que el historiador delinea es adjudicada a la hispanofobia que impregnó a los intelectuales e historiadores argentinos durante décadas:

\footnotetext{
"A fuerza de exageraciones inconsultas y de pretensiones desusadas, que se derivan del empeño de adaptarlo al criterio de Europa, los historiadores hispanófobos le han convertido para ésta quizá, y sin quizá, en un siglo ridículo e ingenuo. El siglo XIX es un trozo de nuestra historia menos hispánica, pues está nutrida de extranjerizaciones peligrosas; pero es un trozo enérgico, lleno de vida anárquica, muy apolítica, poco europea, pero al fin y al cabo nativa" (SILVA, 1918, p. 50)
}

Son variados los elementos que Silva identifica y a la vez construye para caracterizar al siglo XIX y dotarlo de una significatividad política claramente negativa, asumiendo el tiempo de la decadencia que, como se dijo, amenizaba las posibilidades y potencialidades de la unión panhispanista. Así, enumeraba: una evolución política "anárquica"; una inclusión extranjera "irreflexiva"; un proceso "amorfo" del Estado; y la difusión europea no-hispánica. Señalaría, asimismo, que la revolución en toda América española fue provista en movimientos de capitalidad y con una acción comunal: 


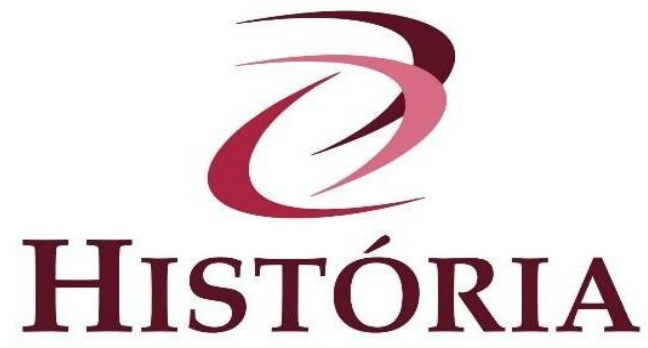

\begin{abstract}
"así fué un localismo de sedes virreinales estimulado por la posición regional, se irradia a las provincias del interior, al ser llevada su intención por la espada de sus tropas, como correspondía a la expansión de un Estado naciente cuyo «typo» poco o nada diferiría del existente — como ha sucedido efectivamente- , aun cambiando la forma Monarquía por República. Esto se efectuó, por ejemplo, en Argentina merced a las expediciones que marcharon al Alto Perú y Paraguay a las órdenes del Coronel Ortiz de Ocampo y del Vocal Manuel Belgrano, cuyos resultados fueron de varia suerte. Sobre todo inútil inmediatamente en el Paraguay, pues se separó de Argentina, e inútil mediatamente en el Alto Perú, pues luego lo abandonaron las tropas argentinas; por fin Bolívar, debido a la mala política porteña, realizó su desmembración de Argentina" (SILVA, 1918, p. 52)
\end{abstract}

La caracterización de la Revolución de Mayo de 1810 introduce la idea de que el otorgamiento de la soberanía popular desorientó a los pueblos. Silva afirmaba que se había implantado una inexacta noción acerca de la política exterior de España durante la época colonial "puesto que las tierras del Nuevo Mundo, afirmamos con criterio eminentemente jurídico, eran partes integrantes de un Imperio, fracciones territoriales de un solo Estado, nunca colonias como se repite retóricamente desde 1810 en los libros" (SILVA, 1918, p. 53. ${ }^{\text {v }}$ Seguidamente amonestaba las "notorias oscilaciones" seguidas por la política argentina: el accionar de "núcleos partidistas sin ideales" y, con ello el "proceso regresivo de descentración” y "la anarquía”(SILVA, 1918, p. 52). Mención aparte merece la situación que, según Silva, atravesaron los pueblos de las provincias:

\footnotetext{
"Sugestionadas las multitudes, habituados los pueblos a la anormalidad y el militarismo con preeminencias, tardíamente se resignaría éste a hacer efectivo el credo que decía afirmaba su espada afortunada, manteniendo entre tanto cautiva a la vida civil, que no podía así formar el Gobierno. Desde 1810 se produce mal en toda América española esa libertad pintoresca preñada de militarismo, de motines, en el cual el elemento civil nunca dió un paso arriesgado sin la inspiración cuartelera; así siempre el concurso de las bayonetas sugirió las deliberaciones gubernativas. La lucha anárquica encontró al caudillaje, y su vida política, juzgada en América española según el criterio del constitucionalismo de la Europa Occidental, era algo insólito para la llamada comunión democrática, que pretende sustentar nominalmente el "espíritu liberal" desde 1810" (SILVA, 1918, p. 54)
}

En su examen mordaz del siglo XIX, el historiador consideró ya para 1850 desvirtuada a la Revolución de Mayo de 1810. Ante sus argumentos, el legado revolucionario había procurado en la mentalidad de sus protagonistas "asegurar estabilidad al liberalismo doctrinario y traducido, en toda América española" (SILVA, 1918, pp. 54-55). Con ello, Silva observaría críticamente "la yuxtaposición efectiva y literal, anti-política y antijurídica" de 


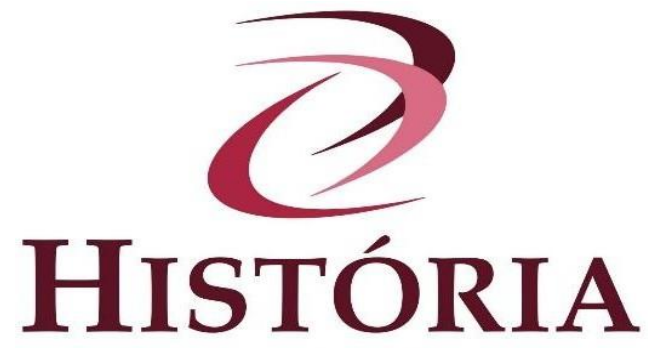

debates e tendências

instituciones "cuya estructura exótica, por ser francés o yankee, sería la negación de lo nacional, vale decir de lo nativo"(SILVA, 1918, pp. 54-55). Seguidamente se dedicó a explicar que la "invasión de inmigrantes" en Argentina había tomado proporciones tan gigantescas por lo que no podía ya hablarse "de un pueblo con cohesión espiritual, a la cual urgentísimamente [sic] toca poner remedio eficaz". Se explaya al respecto:

\begin{abstract}
"En todos los países de nuestra América desde 1810 el contingente extranjero toma proporciones desmesuradas, influyendo en el contenido de la vida nacional; la garantía de la continuidad espiritual del pueblo se pretende lograrla con los paisanos leales a su tradición y con que la dirección política sea ejercida por los nativos legales, en mayoría con relación al elemento extranjero, que sólo creemos justamente debe considerarse al no-hispánico" (SILVA, 1918, p. 56)
\end{abstract}

Se introduce a partir de la cita que antecede la noción de tradición, que Silva identifica con la matriz histórica pan-hispanista de los siglos XVI, XVII y XVIII, a su parecer "seccionada" en pos de garantir de seguridad al "movimiento separatista". No obstante, el historiador exponía:

\begin{abstract}
"A pesar de los ideologismos traídos de Francia y Estados Unidos con el Derecho político que cristalizan con la Constitución y el fetichismo con que a ésta se la mira, y aún más de la fraseología hispanofa [sic] y europeizada, tan en boga a pesar de ser de suyo tan perniciosa, la historia general hispana de tres siglos, XVI-XIX, por lo tanto incorporada a nuestro desenvolvimiento nacional, no está inerme en el alma de la vida popular" (SILVA, 1918, p. 57).
\end{abstract}

Cual sujeto de la historia, "el alma de la vida popular" mantenía viva, según Silva, la llama de la cultura hispana. Desconfiaba de la "palabrería nacionalista" desafectada de España, "ridícula, engañosa y chauvinista". Por ello, saludaba el renacer nacionalista panhispanista de la hora coincidente con la Gran Guerra:

\footnotetext{
"Hoy, con explicable serenidad, se inicia bajo mejores auspicios por una discreta y selecta minoría, (...), ya que ella vela por los fueros inmaculados de la verdad, luchando con inveterados, explicables y vulgares prejuicios antiespañoles que han tomado vuelo - aunque sin ninguna agresividad - los cuales son sustentados por la muchedumbre de las gentes, lo mismo de los que presumen de letrados que de los que son tenidos por analfabetos. Esta tarea se concreta en la preocupación de depurar ante la consideración colectiva, propia y extraña, muestro pasado imperial, que no es otro que todo el tiempo anterior a 1810; considerándolo como un algo que afecta íntimamente y del cual hasta por político interés conviene no interrumpir su vinculación histórica, porque ello representa mantener para la nacionalidad sus energías hispánicas, cuya resta le sería más que peligrosa, fatal, dado que son tan imponderables" (SILVA, 1918, p. 58)
} 


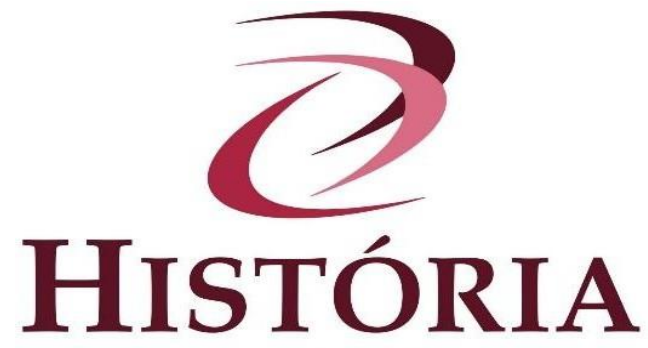

debates e tendências

\title{
Las claves del panhispanismo y la operación revisionista
}

Como en toda operación revisionista, la existencia de un proyecto cultural y político en el que el historiador se halla manifiestamente involucrado, absuelve al escritor de lidiar con la separata temporal que haría del pasado un absoluto distante, trazando una correspondencia activa con el presente (HALPERIN DONGHI, 1970, CATTARUZZA, 2003; RAMA, 1981; KROEBER, 1964; QUATTROCCHI-WOISSON, 1995):

\begin{abstract}
"Esta historia, por ejemplo, en Argentina desde 1810 el puerto de Buenos Aires la quiere hacer y la hace inconsútil, infalible y dogmática, en los libros, en los diarios y en las conferencias y en las escuelas; cuando ella es muy humana y (...) es galardón cierto del orgullo hispánico (...) porque se nutre con el esfuerzo extranjero y cosmopolita desde los albores de su vida patricia y no puede aún prescindir del concurso de los inmigrantes, cuando ella todavía, si hace concebir lisonjeras esperanzas, no ha superado a lo que le precedió antes de 1810" (SILVA, 1918, pp. 138-139)
\end{abstract}

En el caso de J. Francisco V. Silva, el imaginario hispanista conformado en su Córdoba natal y luego desenvuelto en las atmósferas sevillana y madrileña, ofreció de marco de sentido en el que se posicionaba polémicamente frente al presente. En efecto, bajo su prisma no sólo Argentina, sino toda la América española tenían que "despedirse del siglo XIX", aprovechando el "espíritu de las cosas" que la Primera Guerra Mundial estaba dejando expuesto, atestiguando la crisis. La propuesta, que alcanzó cierta difusión desde principios del siglo XX (DEL VALLE, 2011, pp. 465-484) aseguraba que el liberalismo había cumplido ya su ciclo y que los pueblos hispanoamericanos tenían que sacrificarse ante "un superior ideal de Estado propio", "no extranjero"(SILVA, 1918, p. 4). En ese sentido, el panhispanismo era concebido como la reformulación del Imperio Hispánico, es decir, la unión federal entre España y los países de la "América española".

En la imaginación intelectual de J. Francisco V. Silva, sería desde el "centro culto de España" donde el panhispanismo, "respetuoso y tutelar" irradiaría sus mayores esfuerzos. Entre los grandes objetivos enunciados por el historiador, este nuevo proyecto político y cultural posibilitaría una teoría aplicada de los nacionalismos y la "formación del símbolo suficiente para sugerir entusiasmos a la colectividad", un renovado espíritu para esa sociedad de alma nacional joven, débil y agitada por la hispanofobia desde 1810 (SILVA, 1918, p. 


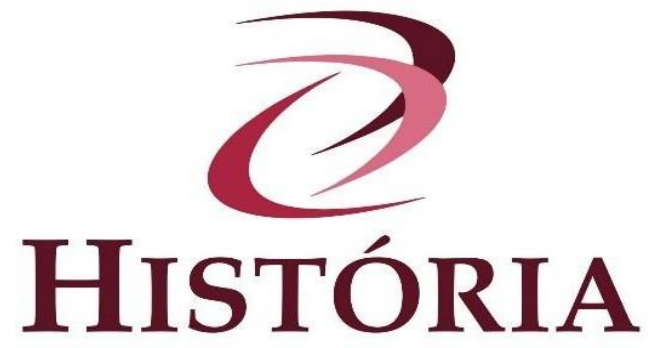

119). Esa colectividad, "vacilante en su destino" aun, estaba formada por argentinos de distinta connotación. Silva entabla al respecto una distinción entre los inmigrantes y los nativos. A saber, los primeros realmente fueron concebidos por el historiador como "argentinos legales", y los segundos como "argentinos étnicos": los indios, los criollos, los gauchos y los hispano-argentinos "por ser España de la misma raza" (SILVA, 1918, pp. 119120). Seguidamente el autor precisaba que si bien, todos los nacidos en el país "pertenecen a una sola familia hispana”, los argentinos étnicos debían afirmar un hispanismo central frente a los argentinos legales, que sostenían un hispanismo formativo: “(...) y entre uno y otro hay distancias que tienen que guardarse únicamente en la dirección nacional. Así en ella debe privar lo puramente clásico y tradicional hispánico, (...), y es intolerable que tal no suceda, pues así se desnacionaliza al país desde 1810” (SILVA, 1918, p. 120).

Para Silva, la colectividad panhispánica no adquiriría su condición nacionalista por un mero hecho de residencia en el país. Al contrario, era el "grupo humano de gentes nativas e indígenas, consolidadas con la cuna por un mínimum de generaciones" lo que animaba el deseo de "seguir una nación en la continuidad del espacio sobre un mismo territorio y en la sucesión del tiempo elaborando una misma Historia"(SILVA, 1918, pp. 120-121). Asimismo, explicitaba que el "pan-hispanismo" se diferenciaba claramente de otros justificados imperialismos como el, pan-germanismo de Alemania, del pan-americanismo de los Estados Unidos, el pan-eslavismo de Rusia y los de Inglaterra y Japón. Según afirmaba, el principal contraste remitía a que el panhispanismo no respondía, como los mencionados, "a una situación agresiva, de expansión de guerra ofensiva". Por el contrario, obedecía "a un plano de conservación, de reconstitución, de guerra defensiva"(SILVA, 1918, p. 20).

En su escritura programática, histórica y política, J. Francisco V. Silva se encargaba de exponer que la capacidad imperialista del pan-hispanismo buscaba "hacer figurar un día a los pueblos hispánicos: España, Portugal, Brasil, América española, unidos en su Imperio, entre las grandes Potencias del mundo", puesto que consideraba que el porvenir de la raza española de ambos mundos estaba, como ya se dijo, en la Unión federal de su Imperio (SILVA, 1918, p. 21). A propósito sostenía que el pan-hispanismo produciría "una movilización de elementos capacitados, y una transfusión de energía entre todos los pueblos hispánicos" que actuaría en la política, en la cultura y en la vida general de ellos. No dudaba, además que el 


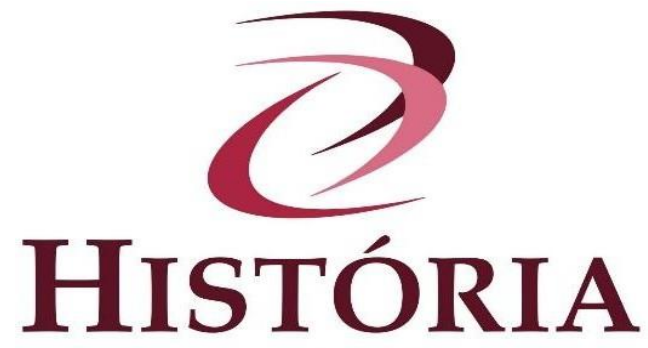

debates e tendências

pan-hispanismo redundaría en una "actividad de renovación eminentemente nacional" capaz de poner en movimiento "valores espirituales, fuerzas materiales y prestigios personales, hasta hoy estancados en los remansos de sus países de origen" (SILVA, 1918, p. 22). ${ }^{\text {vii }}$

Razonablemente, el desafío panhispanista atacaría sin dudas al patriotismo localista o "nacional", aquel que Silva crítica y lúcidamente observaba ligado a la maquinaria de la "burguesía rutinaria" y a la "burocracia anticuada" (SILVA, 1918, p. 23). Esta clase social era, a su entender y efectivamente, la responsable de la desnacionalización de los pueblos hispánicos producida desde 1810: "La "Independencia" de 1810 sobre el territorio del Católico Hispano Imperio, fundó los actuales Estados. Su objetivo fué nacionalizarlos fuera contra y aparte de España. El resultado después de un siglo ha sido inverso: los ha desnacionalizado" (SILVA, 1918, p. 26). Por pueblos hispánicos Silva comprendía al conjunto de España y la América española, sobreentendiendo en aquélla a Portugal y en ésta Brasil; y sostenía que éstos tenían "un olvidado y secular denominador común”, la hispánica civilización:

\begin{abstract}
"En los pueblos hispánicos aisladamente, el ideal mal dicho "nacional" en cada uno; se reúne y confunde en un solo ideal imperial hispánico, el cual es total y comprensivo a todos ellos. Él tiene como motores el poder y el dominio en su más alta inspiración. La burguesía capitalista de América española con vanidad y arrogancia de arrivismo [sic] y llena de una odiosa hispanofobia, querrá seguir en su egoísmo insular iniciado en 1810; mas luchará con la aristocracia de sentido demócrata hispánico y con los proletariados de campo y ciudad famélicos de una política social desconocida aún allí a pesar de su vigencia en Europa" (SILVA, 1918, pp. 28-29)
\end{abstract}

Centralmente, el panhispanismo partía de un singular examen de la política seguida por las burguesías liberales luego de la Independencia. Desde su ángulo, J. Francisco V. Silva emplazaba directamente a "desautorizarla" (SILVA, 1918, p. 31). La fundación del Imperio de los pueblos hispánicos requeriría, de acuerdo planteaba el historiador, revisar la estructura y el contenido del Estado, “porque acoplar en la Unión federal tal como están los actuales Estados de España y América española es una contradicción in adjecto con la idea del Imperio. Así la revisión de su derecho codificado, de su administración técnica y de sus leyes dispersas, serían las primordiales plataformas de su formación" (SILVA, 1918, p. 31).

Asimismo, se llamaba a repudiar todo ese "bagaje inútil, retórico y espúreo [sic]" representado por "ese militarismo de escalafón, ese socialismo de soneto, ese pacifismo ramplón, esa enseñanza de exámenes, esa propiedad de latifundios" propios del siglo XIX 


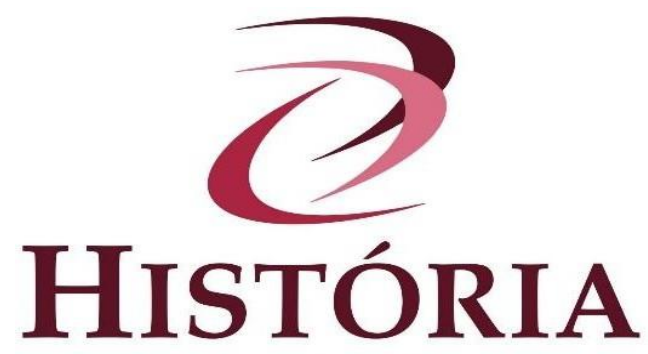

debates e tendências

tanto en España como en la América española(SILVA, 1918, pp. 31-32). Esta situación habría de cambiar mediante el pan-hispanismo, cuando los pueblos hispánicos desarrollaran en el concreto histórico una, "su" misión: la de enarbolar una bandera como heraldo de paz y símbolo de una democracia de hombres (SILVA, 1918, p. 137). Así:

"El vivo y fuerte sentimiento nacional de Imperio debe exaltar el ánimo popular Y entrever días próximos del más puro hispanismo, días capaces de contener la impulsión en la ruta hacia el abismo, al que caen los pueblos de América española desde 1810 cuando reniegan del llamado de su misión y así se precipitan en la sombra del olvido, pasando sin gloria y sin historia, como tránsfugas de la lealtad para con España, la nación imperial que los guió y los formó en su unidad de civilización" (SILVA, 1918, p. 139).

\section{A propósito de las causas y el significado histórico de la desmembración del territorio argentino}

El trabajo revisionista de J. Francisco V. Silva despejó tanto causas geográficas como históricas para examinar la "evolución progresiva de la desmembración" del territorio argentino. Así, a cada espacio desmembrado el historiador le asignó dos "concausas":

\begin{tabular}{|c|c|c|}
\hline \multirow[t]{2}{*}{ Paraguay } & $\begin{array}{c}\text { Causa } \\
\text { geográfica }\end{array}$ & $\begin{array}{l}\text { El "alejamiento geográfico" por su situación mediterránea. La sola vía fluvial } \\
\text { que lo comunica al mar adquiere una distancia desproporcionada y le permite } \\
\text { una medida comunicación interprovincial. Sus relaciones comerciales son } \\
\text { limitadas por la carencia de rutas propias. Su territorio limítrofe está } \\
\text { interrumpido naturalmente en su continuidad geográfica por el río Paraná, que } \\
\text { establece un límite en las zonas de su curso Sur y Este, envolviéndole. } \\
\text { Las tribus indias chaqueñas le interceptan su comunicación terrestre. Los indios } \\
\text { moradores no ofrecen seguridad a través de sus asientos y poblados para el } \\
\text { intercambio. Su régimen de población tiene una individualidad diferente dentro } \\
\text { del Virreinato, con su sistema de encomiendas y población en manos de los } \\
\text { jesuitas convertido en misiones. }\end{array}$ \\
\hline & $\begin{array}{c}\text { Causa } \\
\text { histórica }\end{array}$ & $\begin{array}{l}\text { La autonomía en que vivió desde el inicio de la conquista concentró su } \\
\text { aislamiento con el resto del Virreinato: fue segregación a través del criterio de } \\
\text { los padres jesuitas, que convirtieron el más allá de sus fronteras en un absoluto } \\
\text { desconocido para los indios. Éstos, "llevaron al centro mismo del Nuevo } \\
\text { Mundo Sur el socialismo incásico, evolucionado por la teoréfica [sic] católica y } \\
\text { las adaptaciones de las utopías europeas, inaplicables en Viejo Mundo". }\end{array}$ \\
\hline
\end{tabular}

\begin{tabular}{|c|c|l|l|}
\hline Uruguay & $\begin{array}{c}\text { Causa } \\
\text { geográfica }\end{array}$ & $\begin{array}{l}\text { Su situación litoral estimula su historia y también fue su base decisiva. Por } \\
\text { efecto del litoral marítimo se aboca al comercio general, y por la continuidad } \\
\text { geográfica existente en su N.E., dada la falta de accidentes orográficos } \\
\text { fronterizos, encuentra fáciles comunicaciones comerciales con las fierras del } \\
\text { Río Grande y las antiguas Misiones argentinas. La costa atlántica es } \\
\text { proporcionalmente extensa y su frontera sobre ella da fácil acceso. }\end{array}$ \\
\hline
\end{tabular}




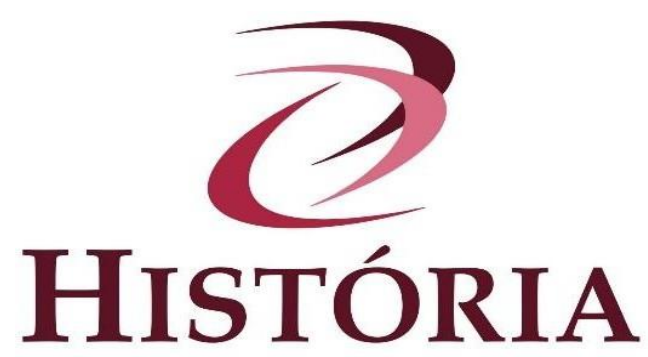

debates e tendências

\begin{tabular}{|c|c|c|}
\hline $\begin{array}{c}\text { Causa } \\
\text { histórica }\end{array}$ & $\begin{array}{l}\text { La rivalidad portuguesa en la frontera del Este virreinal. La Banda Oriental se } \\
\text { vio limítrofe con el rival inicial y la situación azarosa de la guerra constante le } \\
\text { solicitaba hacia la órbita de acción brasilera, desvinculándole con el resto del } \\
\text { Virreinato, favoreciendo su segregación. }\end{array}$ \\
\hline
\end{tabular}

\begin{tabular}{|c|c|l|}
\hline Alto Perú & $\begin{array}{c}\text { Causa } \\
\text { geográfica }\end{array}$ & $\begin{array}{l}\text { Su internamiento acentúa su falta de cohesión con el excedente del país. Su } \\
\text { litoral marítimo relativamente limitado da al Pacífico y no ofrecía facilidad para } \\
\text { el comercio general en la época de la conquista. Establecido el sistema del } \\
\text { servicio marítimo para el comercio de España y el Nuevo Mundo por el } \\
\text { régimen del monopolio, común en Europa entonces, tuvo sus grandes rutas por } \\
\text { Panamá y Callao, después por Buenos Aires, directo a Cádiz, con lo cual el } \\
\text { litoral llamado altoperuano no participó del comercio mayor. }\end{array}$ \\
\cline { 2 - 3 } & $\begin{array}{l}\text { Causa } \\
\text { histórica }\end{array}$ & $\begin{array}{l}\text { Su proximidad al Virrey en casi todos los tiempos acentúa su falta de cohesión } \\
\text { con el excedente del país. } \\
\text { Siguió las alternativas de la guerra y aun con las victorias de Salta y Tucumán } \\
\text { ganadas por Manuel Belgrano, no cesó su cautividad en las armas del Rey. } \\
\text { Fuemenester la expedición de José de San Martín por vía cuyana, que inició el } \\
\text { fin de la resistencia realista en sus tierras y limítrofe Oeste en ocupación } \\
\text { militar, para que vislumbrara su próxima separación del Imperio español, } \\
\text { cumplida militarmente por Bolívar en Junín y por Sucre en Ayacucho. }\end{array}$ \\
\hline
\end{tabular}

\begin{tabular}{|c|c|c|}
\hline \multirow[t]{2}{*}{$\begin{array}{c}\text { Buenos } \\
\text { Aires }\end{array}$} & $\begin{array}{c}\text { Causa } \\
\text { geográfica }\end{array}$ & $\begin{array}{l}\text { La posición marítima sobre el Atlántico guarda relación con el desarrollo de su } \\
\text { costa, con fácil acceso por sus puertos naturales que le favorecen a que su } \\
\text { interior tenga una cómoda salida al litoral. Ofrece mayores ventajas que la costa } \\
\text { uruguaya, sus puertos sirven de bases marítimas en la navegación de la costa } \\
\text { Sur atlántica y del Estuario y éste le asegura el dominio de la red fluvial } \\
\text { argentina. }\end{array}$ \\
\hline & $\begin{array}{c}\text { Causa } \\
\text { histórica }\end{array}$ & $\begin{array}{l}\text { Su función histórica se manifiesta en una situación adquirida en los siglos de la } \\
\text { conquista, reforzada considerablemente en la vida libre desde } 1810 \text {. Tenencia } \\
\text { del puerto de Buenos Aires como tránsito obligado del Interior, adquiriendo su } \\
\text { mayor desarrollo con la implantación del comercio libre en 1778. Luego y sin } \\
\text { el concurso apreciable del Interior, se defendió Buenos Aires cuando las } \\
\text { invasiones inglesas, lo que llevó a su espíritu la convicción de tener ya una } \\
\text { fuerza bastante para la defensa del suelo y también vio la importancia del } \\
\text { puerto codiciado. } \\
\text { Presenció el movimiento de Mayo monopolizándolo y durante su desarrollo } \\
\text { posterior se agitó un privilegio local llevado a contraponerse y detentar } \\
\text { primacía sobre el Interior, lo cual logrado entonces, persiste aun siendo una } \\
\text { opresión de Argentina. Monopolizó también la dirección gubernativa. Todo ello } \\
\text { llevó al ánimo de sus habitantes una vitalidad propia, que adquiriera sus } \\
\text { proyecciones palpables en la dirección política y el ejemplo de la otra banda del } \\
\text { Río, influyó lo bastante para producir la escisión nacional en la primera } \\
\text { desinteligencia, lo que ocurrió cuando la Constitución Nacional se sancionó en } \\
1853\end{array}$ \\
\hline
\end{tabular}

Luego de establecer las "concausas" históricas y geográficas anteriormente sintetizadas, Silva se dedicó a reconocer e interpretar lo que él llamaba "el significado de la desmembración", en el tiempo y en el espacio, para así "considerarla en relación con su valor, 


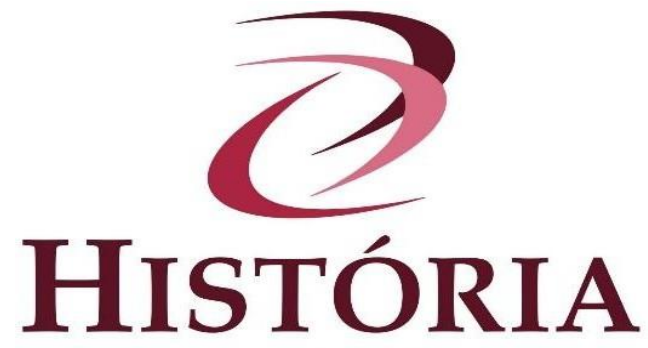

como ser, en el significado que tiene para la historia nacional más cercanamente, y en la historia política general de un modo más mediato, para hallar su continuidad en la vida hispánica" (SILVA, 1918, p. 109). Nuevamente se hace presente el imperativo político de la finalidad panhispanista, cuando al historiador le interesaba encontrar el hilo conductor de la historia para iluminar el sombrío y extraviado panorama hispanoamericano y argentino de 1918:

"El significado de la desmembración es un hecho impuesto a la política argentina, leal a 1810; vale por tanto decir, que debiera tener un alcance próximo en la orientación gubernativa y reconocer una preocupación en el deseo popular. Derívase la imposición que ocupa este hecho, de aquellas sucesiones del obrar colectivo, las cuales, transcendiendo del tiempo y caracterizando a la nacionalidad, representan de un modo más tangible el espíritu de la misma" (SILVA, 1918, pp. 109-110)

Silva remarcaba que la persistencia de la desmembración, en cuanto representa la aceptación del hecho consumado, llevaría al pueblo a abocarse en determinado momento a la “revisión de aquella parte en sí variable de su pasado". En efecto, explicaba que a pesar de la desmembración virreinal que fraccionó el territorio, la historia no había socavado absolutamente a la hispanidad. En ese sentido, ésta, por tener su formación antes de 1810, persistía a las limitaciones políticas y concordaba con los contenidos de raza y tradición(SILVA, 1918, p. 113). Así, a la luz de la "filosofía histórica", Silva reseñaba de esta manera la desmembración virreinal:

\begin{abstract}
“(...) el Paraguay se pierde por el afán simiesco de la primera Junta de Buenos Aires en copiar a la Revolución francesa entregando el mando militar a un civil: Belgrano, sólo por un romanticismo político. El Alto Perú se pierde porque, rechazadas las tropas patriotas por el Ejército del Rey tras Vilcapujio y Ayohuma, quedó olvidado ese territorio, y cuando la proximidad de Bolívar debió aconsejar al Gobierno de Buenos Aires a congraciarse con el General victorioso, para obtener esas provincias, tal no se hizo, y ya es sabido cómo decretó Bolívar la fundación de una República. El Uruguay se pierde porque la soberanía argentina era precaria, sin fuerzas para hacerse respetar; así ocurre que una gran Potencia [sic] europea como Inglaterra, interviniera en el derecho de Argentina, porque convenía a su política marítima que no dominara sobre ambas márgenes del Río de la Plata. Y la de Buenos Aires se reintegró, cuando el descentramiento nacional hubo hecho crisis tan honda que se presentó intolerable, y entonces la voluntad argentina —es decir, las provincias-: arremetió fieramente y triunfó" (SILVA, 1918, pp. 113-114)
\end{abstract}

Avanzando sin recaudos en "contra el hispanófobo criterio anticientífico en la Historia aún vigente" Silva concebía que para la pérdida del territorio virreinal "no poca influencia tuvo el proceder despótico de Buenos Aires, revelador de un estrecho parroquianismo" 


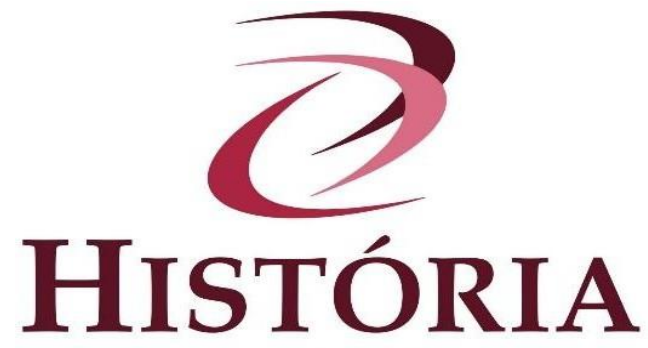

(SILVA, 1918, p. 115). Tras ello, el historiador impugnó el accionar del liberalismo porteño al "herir el sentimiento nacional fusilando al vencedor de la Reconquista, a Liniers y sus compañeros en "Cabeza del Tigre", lastimando históricamente "el sentimiento religioso con las irreverencias de Castelli en Cochabamba"; y, finalmente lesionando "el sentimiento localista con el abominable trato que empleó con Artigas". Se trató, según consideraba J. Francisco V. Silva, de una política sin ruta, a su tiempo impugnada por hombres "del Interior" como el Deán Gregorio Funes y Juan Bautista Alberdi, aunque enaltecida por "los historiadores hispanófobos, porteños o aporteñados" (SILVA, 1918, p. 115).

La resultante de la pérdida de la unidad territorial fue concebida por el autor "con espíritu realista opuesto al sentimentalismo histórico antijurídico, vigente en América española desde 1810". Por ejemplo, afirmaba que como producto de esa historia Argentina quedaba condenada a ser casi un país mediterráneo porque el litoral que le quedaba era en el sur, zona extensa aunque inadecuada para el comercio con los países manufactureros de Europa(SILVA, 1918, pp. 125-126).

\section{A modo de cierre}

En este trabajo se ha procurado una lectura de los usos del espacio y de la historia en la programática política de la historiografía en el "revisionismo 'anterior' al Revisionismo", en este caso en la escritura de J. Francisco V. Silva (Córdoba, Argentina, 1890-1978). Este intelectual puede integrarse al paisaje compuesto por quienes, en el contexto mayor de la crisis cultural provocada por la Primera Guerra Mundial, traccionaron un conjunto de novedades políticas y sensibilidades de una modernidad conservadora dispuesta a imaginar/construir el futuro apostando a un reencuentro con el pasado hispánico en acto de alianza imperial defensiva contra las pretensiones norteamericanas y el accionar de las burguesías liberales locales.

Como sujetos interpretativos y de acción, muchos hombres de letras americanos visualizaron en España un verdadero Norte político y moral y un entronque histórico posible vía tradición, en la revitalización de algunas pautas de sentido histórico largamente combatidas por la modernidad liberal ejercitada por las clases dominantes durante el largo 


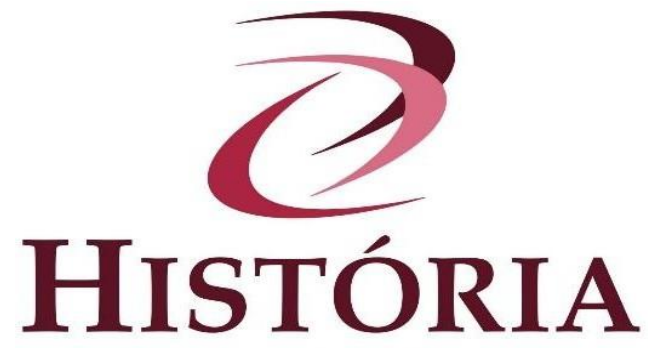

debates e tendências

siglo XIX. En ese sentido, el estudio de los textos que constituyen el corpus de escritos de Silva, sobre todo los de su tiempo de estancia y mayor contacto con España hacia 1914, año en que leyó su Tesis Doctoral en Derecho en la Universidad de Alcalá -1948-Central de España (SILVA, 2014), y 1918, debiera considerar la circulación de lecturas circundantes y las interferencias de las claves del contexto, así como no renunciar a leer su capacidad creativa-disruptiva que como se observó, fue fecunda.

Entre las hipótesis que estructuraron complejamente la mirada política e historiográfica del historiador revisionista, y como se leyó en este artículo, se encuentra la tesis de que la desmembración territorial de la América hispana fue una acción vinculada a los intereses de las ideologías desnacionalizadoras del siglo XIX, afines al capitalismo tanto inglés como norteamericano, que soñó con extirpar el corazón moral y cultural de siglos español. De esta manera, Silva se abocó sistemáticamente a describir y ofrecer una interpretación histórica y política de las razones y derivas de esa partición espacial, invocando y esgrimiendo saberes geográficos, históricos y "politológicos", operación que resultaría en una ambiciosa puesta a punto de la historicidad del proceso mediante el cual "la Argentina" extravió el camino hacia el progreso.

De esta manera, se comprueba la feracidad del afán revisionista, los encuadres de su cometido y se constata su complejidad. J. Francisco V. Silva propuso una interpretación de la historia argentina y americana acudiendo a una imaginación histórico-territorial de corte subcontinental antes que localista. Esta característica lo sitúa en una dimensión poco explorada por la historia de la historiografía, que tiende usualmente a remitir a los historiadores y a sus discursos a universos más acotados, desprovistos a veces de sus redes de referencias intelectuales y sin contemplar la importancia de comunidades interpretativas mayores que las de sus respectivas nacionalidades.

\section{Fuentes}

SILVA, Juan Francisco Vicente. Concepto Moderno del Estado. Introducción a un Estudio del Municipio Federal. Madrid: Librería General de Victoriano Suárez, 1914. 


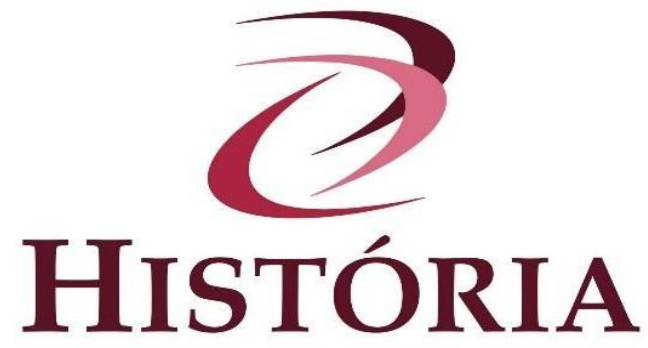

debates e tendências

SILVA, Juan Francisco Vicente. La desmembración del territorio argentino en el siglo XIX. Madrid: Real Sociedad Geográfica, 1915. [Conferencia dada en la Real Sociedad Geográfica en su sesión pública del 3 de diciembre de 1914]

SILVA, Juan Francisco Vicente. Reparto de América Española y Pan-Hispanismo. Madrid: Francisco Beltrán, 1918.

\section{Referencias bibliográficas}

BUCHBINDER, Pablo. La Nación desde las provincias: las historiografías provinciales argentinas entre dos Centenarios. Anuario del Centro de Estudios Históricos "Prof. Carlos S. A. Segreti”. N 8, 2008, pp. 163-182.

CATTARUZZA, Alejandro. El revisionismo: itinerarios de cuatro décadas. En:CATTARUZZA, Alejandro y EUJANIAN, Alejandro. Políticas de la Historia. Argentina, 1860-1960. Buenos Aires: Alianza, 2003, pp. 143-182.

CATTARUZZA, Alejandro y EUJANIAN, Alejandro. La cuestión de Rosas a fines del siglo XIX: Saldías y Quesada. En: JITRIK, Noé (dir.). Historia crítica de la literatura argentina. Buenos Aires: Emecé, 2010, pp. 559-580.

CHIARAMONTE, José Carlos y BUCHBINDER, Pablo. Provincias, caudillos, nación y la historiografía constitucionalista argentina. Anuario del IEHS. No VII, 1992, pp. 93-120.

CHIARAMONTE, José Carlos. Usos políticos de la historia. Lenguaje de clases y revisionismo histórico. Buenos Aires: Sudamericana, 2014.

DEL VALLE, José. Panhispanismo e hispanofonía: breve historia de dos ideologías siamesas. Sociolinguistic. Vol. 5. 3., 2011, pp. 465-484.

DEVOTO, Fernando. El revisionismo histórico. En: DEVOTO, Fernando y PAGANO, Nora. Historia de la historiografía argentina. Buenos Aires: Sudamericana, 2009, pp. 201-285.

ESCUDERO, Eduardo. El historiador J. Francisco V. Silva: la consistencia de la trama entre hispanismo, revisión historiográfica y proyecto político. Anuario del IEHS. Vol. 33, $\mathrm{N}^{\circ} 2$, 2018, pp. 19-37.

ESCUDERO, Eduardo y ROJAS, Agustín. En torno a la historiografía cordobesa finisecular y el momento de las crónicas provinciales: el caso de Ignacio Garzón. En: BREZZO, Liliana y MICHELETTI, María Gabriela (comps.). $V^{a}$ Jornada de discusión de avances de investigaciónen Historia Argentina: fuentes, problemas y método. Rosario: Instituto de Historia, Facultad de Derecho y Ciencias Sociales del Rosario, UCA Nodo Rosario - UER / IDEHESI-CONICET, 2014, pp. 1-19. 


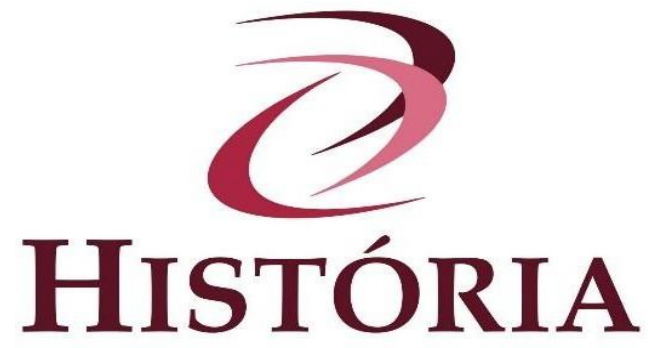

debates e tendências

HALPERIN DONGHI, Tulio. El revisionismo histórico argentino. Buenos Aires: Siglo XXI, 1970.

KROEBER, Clifton B. Rosas y la revisión de la historia argentina. Buenos Aires: Fondo Editor Argentino, 1964.

LEVENE, Ricardo. Las Indias no eran colonias. Madrid: Espasa-Calpe, 1973 [1951].

MICHELETTI, María Gabriela. Facundo Quiroga rehabilitado. Una aproximación al contexto de producción, repercusiones y aportes historiográficos del libro de David Peña (1906). Boletín del Instituto de Historia Argentina y Americana "Dr. Emilio Ravignani". 3ra. serie, $\mathrm{N}^{\mathrm{o}}$ 42, 2015, pp. 125-153.

PALACIO, Ernesto. La historia falsificada. Buenos Aires: Difusión, 1939.

PASCUARÉ, Andrea. Del Hispanoamericanismo al Pan-hispanismo. Ideales y realidades en el encuentro de los dos continentes. Revista Complutense de Historia de América. $\mathrm{N}^{\circ} 26$, 2000, pp. 281-306.

PÉREZ AMUCHÁSTEGUI, Antonio J. El historiador Ernesto Quesada. En: FERRARI, Gustavo y GALlO, Ezequiel (comp.). La Argentina del 80 al Centenario. Buenos Aires: Sudamericana, 1980, pp. 841-849.

QUATTROCCHI-WIOSSON, Diana. El Revisionismo de los años 20 y 30. Rosistas y revisionistas ¿los rivales de la historia académica? En: GIRBAL DE BLACHA, Noemí [et al.1 La Junta de Historia y Numismática y el movimiento historiográfico en la Argentina (1893-1938). Buenos Aires: Academia Nacional de la Historia, 1995, pp. 295-315.

QUIÑONEZ, María Gabriela. Prólogo: hacia una historia de la historiografía regional en la Argentina. En: SUÁREZ, Teresa y TEDESCHI, Sonia (comps.) Historiografía y sociedad. Discursos, instituciones, identidades. Santa Fe: Universidad Nacional del Litoral, 2009, pp. 5-18.

RAMA, Carlos. Nacionalismo e historiografía en América Latina. Madrid: Tecnos, 1981.

REALI, María Laura. Al margen de 'El Relato'. Circulación transnacional de lecturas revisionistas sobre el pasado en América Latina (1900-1930). Nuevo Mundo Mundos Nuevos [En línea], $2016 \quad$ [Consulta: 12/02/2020]Disponible en <http://nuevomundo.revues.org/69313Laura Reali>.

ROJAS, Agustín. Esas otras historias del interior. Aproximación al locus cordobés desde las crónicas hasta el proceso de institucionalización (1884-1956). En: PHILP, Marta (comp.). Operaciones historiográficas en contexto. Córdoba: CEA/UNC, 2017, pp. 29-49. 


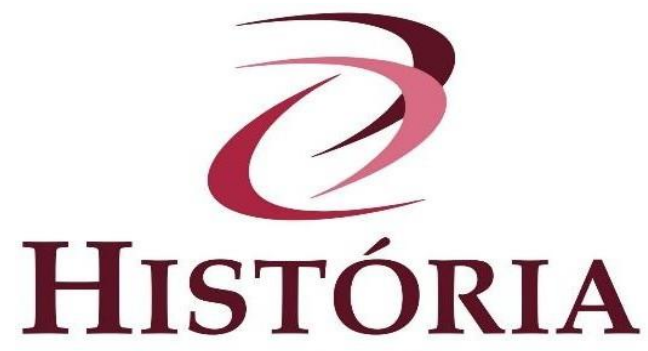

debates e tendências

Recebido: 19/01/2021

Aceito: 20/08/2021

Publicado: 18/02/2022

${ }^{\text {i }}$ Doctor en Historia por la Facultad de Filosofía y Humanidades de la Universidad Nacional de Córdoba, Argentina. Docente e investigador en la Universidad Nacional de Río Cuarto y en la Universidad Nacional de Córdoba, Argentina. http://orcid.org/0000-0002-0507-1719

iiSimilares conceptos vertería veinte años después una figura medular del revisionismo rosista de los años treinta (PALACIO, 1939).

iii La desmembración del territorio argentino en el Siglo XIX [Conferencia dada en la Real Sociedad Geográfica en su sesión pública del 3 de diciembre de 1914], Madrid; La Argentina del siglo XVI (con documentos y gráficos), Madrid; El Libertador Bolivar y el Deán Funes. Revisión de la Historia Argentina. Editorial América, Madrid, 1917; La desnacionalización de la Historia Argentina del siglo XIX [Conferencia dada en la Real Sociedad Geográfica en su sesión pública del 4 de junio de 1917], Madrid; La solidaridad de los pueblos hispánicos [Originalmente publicado en la Revista Nuestro Tiempo, № 222, Madrid, junio de 1917, pp. 275316], Madrid; El Generalísimo San Martín (con documentos y mapa), Madrid; Argentina bajo. la opresión de Buenos Aires desde 1810. Historia interna y política económica (con estadísticas y gráficos), Madrid, 1918; Manual de Historia de Argentina. Lecciones. Lecturas y gráficos, Madrid; Inglaterra contra el Imperio de España y "La Dragonites" (siglo XVI), Madrid, 1918; Elogio de Vaca de Castro por Antonio de Herrera. Introducción, edición Leyes Nuevas, Madrid, 1918; De Geografía histórica de América Española (siglo XVII), Madrid; Manual de Historia de América Española, Madrid; Constituciones Complutenses de Ximénez de Cisneros, Madrid, 1918; La Majestad del Imperio en España (siglo XVI), Madrid; Derecho de Real Patronato de Indias (siglo XVIII), Madrid, 1918; El Católico Hispano Imperio (1492-1810), Madrid; Manual de Historia del Derecho de Indias. Instituciones de Imperio, Madrid; Manual de Derecho Constitucional comparado de América española, Madrid; Política geográfica del Pan hispanismo, Madrid, 1918; Historia y Política interhispánica, Madrid.

iv 1934 se presentaría como un "año decisivo" en cuanto la publicación de La Argentina y el Imperialismo británica de Julio y Rodolfo Irazusta, obra que condensaría el modus operandi del revisionismo histórico nacionalista "clásico" en la Argentina (DEVOTO, 2009, p. 221).

Esta posición sería equivalente a la tomada por el historiador liberal Ricardo Levene, décadas más tarde (1951). $\mathrm{v}$ Las cursivas pertenecen al original.

vi Las cursivas corresponden al original. 